\title{
Optimization of Band Pass Filter for Variance Reduction in Determining The Solution of Moment Tensor and Focusing Mechanism with ISOLA-GUI Sequence of The Minahasa Peninsula Earthquake Date 28 September 2018 to 1 October 2018
}

\author{
Titi Anggono $^{1 *}$, Rio Rinaldo Tarigan ${ }^{2}$ and Diana Alemin Barus ${ }^{3}$ \\ ${ }^{I}$ Physics Research Center, Indonesian Institute of Sciences PUSPITEK Area, Building 440-442, \\ Muncul, Setu, Tangerang Selatan, Banten 15314 \\ ${ }^{2,3}$ Department of Physics, Faculty of Mathematics and Natural Science, Universitas Sumatera Utara, \\ Medan 20155, Indonesia
}

\begin{abstract}
Sulawesi is one of the islands in Indonesia with a high level of seismicity because there are many active faults, especially in the Minahasa Peninsula area. This study discusses the moment tensor solution and the focus mechanism in the Minahasa Peninsula region from 28 September 2018 to 1 October 2018 using the ISOLA-GUI program. This program is used to process seismic data from the three components recorded by the seismogram. The data used in this study were five earthquake events consisting of earthquake foreshock, earthquake mainshock, and earthquake aftershock. With the ISOLA program, data processing is carried out which includes: crustal models, event info, selecting earthquake recording stations, preparing raw data for defining seismic sources, calculating green functions with computations, performing inversions and plotting results. In the inversion, the frequency of the band pass filter is selected to obtain the optimal reduction variance. After processing, calculating and interpreting the plot results, a fault model is obtained for each earthquake event, namely strike-slip. The magnitude of the earthquake mainshock moment tensor are $M_{r r}=-1.068 \exp 19, M_{t t}=-3.630 \exp 19, M_{p p}=$ $4.698 \exp 19, M_{r t}=2.460 \exp 19, M_{r p}=-2.655 \exp 19, M_{t p}=-2.744 \exp 19$.
\end{abstract}

Keyword: moment tensor, focus mechanism, Green function, inversion, fault.

Received 19 August 2021 | Revised [23 August 2021] | Accepted [27 August 2021]

\section{Introduction}

Sulawesi is one of the islands in Indonesia with a high level of seismicity; this happens because in Sulawesi there are several active faults that cause geological disasters [1-5]. The Palu Koro Fault is one of the most active faults in the Sulawesi region which causes frequent geological disasters in this region [1]. One of them was the earthquake that occurred in Palu and Donggala in September 2018 with an earthquake magnitude of 7.5 which was followed by other

*Corresponding author at: Indonesian Institute of Sciences PUSPITEK Area, Building 440-442,

Muncul, Setu, Tangerang Selatan, Banten 15314

E-mail address: titi.anggono@gmail.com 
geological disasters such as the tsunami. and liquefaction. Earthquakes have different characteristics depending on the geological conditions of the area [1].

One way to determine the characteristics of an earthquake is to estimate the moment tensor and the mechanism of the earthquake focus. Earthquakes as the effect of the breaking of rock masses that cause seismic waves are recorded at the station using a three-component seismometer. A three-component seismometer is a seismometer that has three sensors [6-8].

The modeling of the earthquake focus mechanism and moment tensor is used to describe the direction of the force causing the earthquake which is described by a beach ball and based on the calculation of the Green function and the inversion of the three-component waveform. By using the moment tensor inversion, the earthquake source process in detail can be determined by observing the data recorded by the seismogram. The results of this analysis are in the form of earthquake parameters which include: hypocenter, magnitude, moment tensor, earthquake energy and fault models that cause earthquakes [9-11].

According to the theory of plate tectonics, the earth's crust will be broken up into pieces called plates. The plates will continue to move in different directions. Based on convection theory, movement is caused by convection currents. Arthur Holmes and Harry H. Hess and further developed by Robert Diesz, stated that in the hot and glowing earth, convection currents occur in the direction of the earth's crust above it, so that when convection currents carrying material in the form of lava reach to the earth's surface at the mid-oceanic ridge [9].

When an earthquake occurs, the strain energy caused by the breaking of rocks due to mechanical events (push, shear, tensile) is then transferred into wave energy. From the focus of the earthquake, the earthquake waves will propagate in all directions, one of which is reaching the ground surface. Before reaching the earthquake wave recording device, it will pass through various layers of rock/soil. Some of the waves will be reflected, refracted and some will move along the ground surface.

In general, earthquake waves can be divided into body waves, namely waves that propagate within the earth and surface waves, namely waves of earthquake energy that propagate on the earth's surface [12-15].

\section{Methods}

\subsection{Data}

The data used is data on earthquake events that occurred in the flinn Engdahl Minahasa Peninsula on 28 September 2018 to 1 October 2018 as many as 5 earthquake events consisting 
of foreshock, mainshock and aftershock earthquake. These data were obtained from GFZ postdam.

The software used in data processing include; MATLAB R2012a, ISOLA GUI as main program, General Mapping Tools (GMT)4 for plotting maps run ISOLA-GUI added to system paths, M_map for plotting maps added to MATLAB toolbox, GSHHG (Global Self-consistent Hierarchical High resolution Geography) Database) added to M_map, Ghoshcript and GSview to plot the moment tensor solution added to system path and notepad++ to create .pz files and .stn files and to display copies of Green function calculations.

\subsection{Data processing}

Seismic wave data that has been converted into SAC form is used in the ISOLA program to determine the moment tensor and focus mechanism. The ISOLA program is run in Matlab. Before processing the three-component seismic wave data, the station data and pzfile are prepared from the RESP file. Then the station data and pzfile are saved into ISOLA. The following is the main ISOLA display used to process data [16-17].

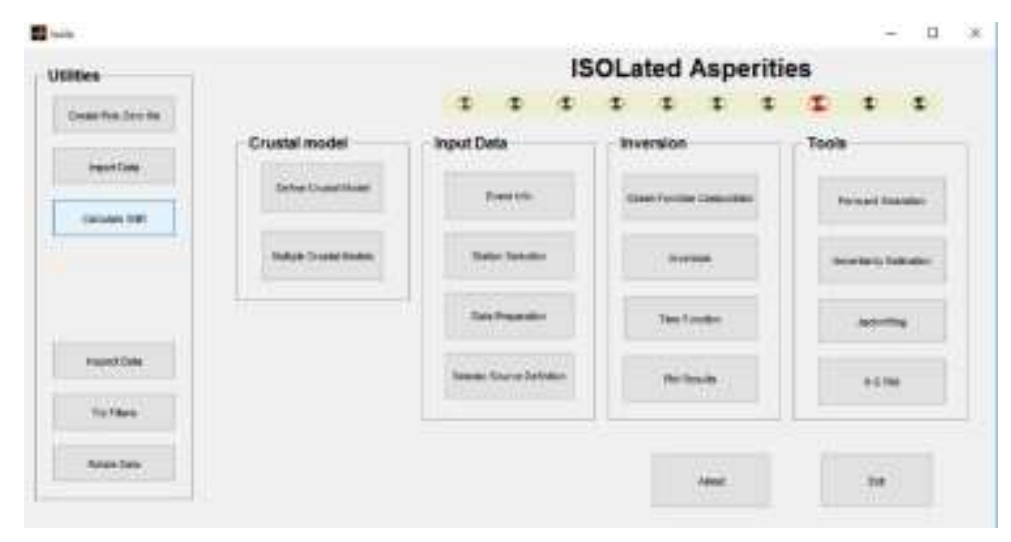

Figure 1. ISOLA Program

Then the SAC data is imported into ISOLA, defines a crustal model, which includes a model of the speed of wave propagation in the earth, input earthquake data (event info), station selection, preparation of raw data, correction instruments, and then saved time adjustment. Then do the computation with the Green function, the calculation of the Green function is saved automatically into ISOLA and performs the inversion and plots the results. 


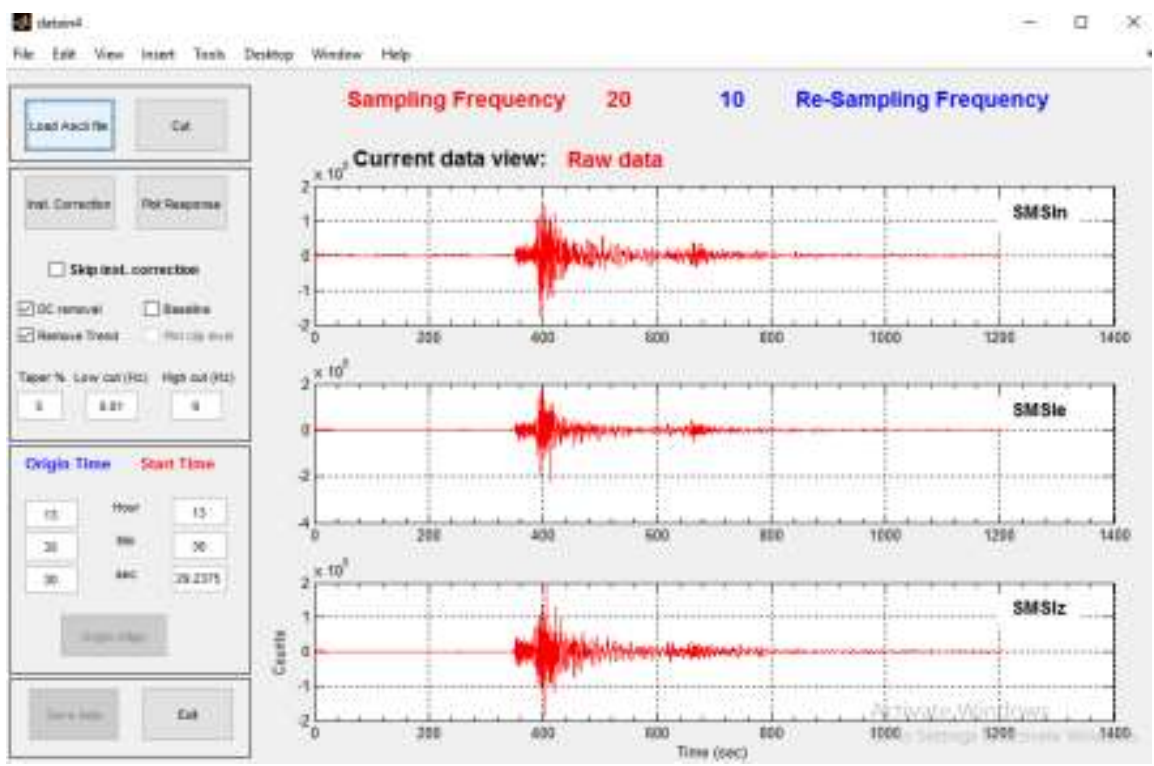

Figure 2. Data correction process for each station, correction instrument

\section{Result and Discussion}

\subsection{Synthetic and observation curve}

The result of processing the seismogram data is the calculation of the Green function and continued with inversion to produce a synthetic curve from the calculation with the curve recorded by the seismogram. To measure the optimality of the inversion, the value between the calculation curve line and the curve recorded by the seismogram is close to parallel. The optimal inversion process can be seen in the value of the reduction variance [18]. The value of the reduction variance will be better if the value is close to 1 . According to Stein \& Wysession (2003) events like this can occur because of the elastic nature of the layer medium through which seismic waves pass8. This can be seen from the results of matching the observation data and synthetic data from the investment results, good results occur when the observation data and synthetic data overlap each other. Plot the results of the curve as shown below [19].

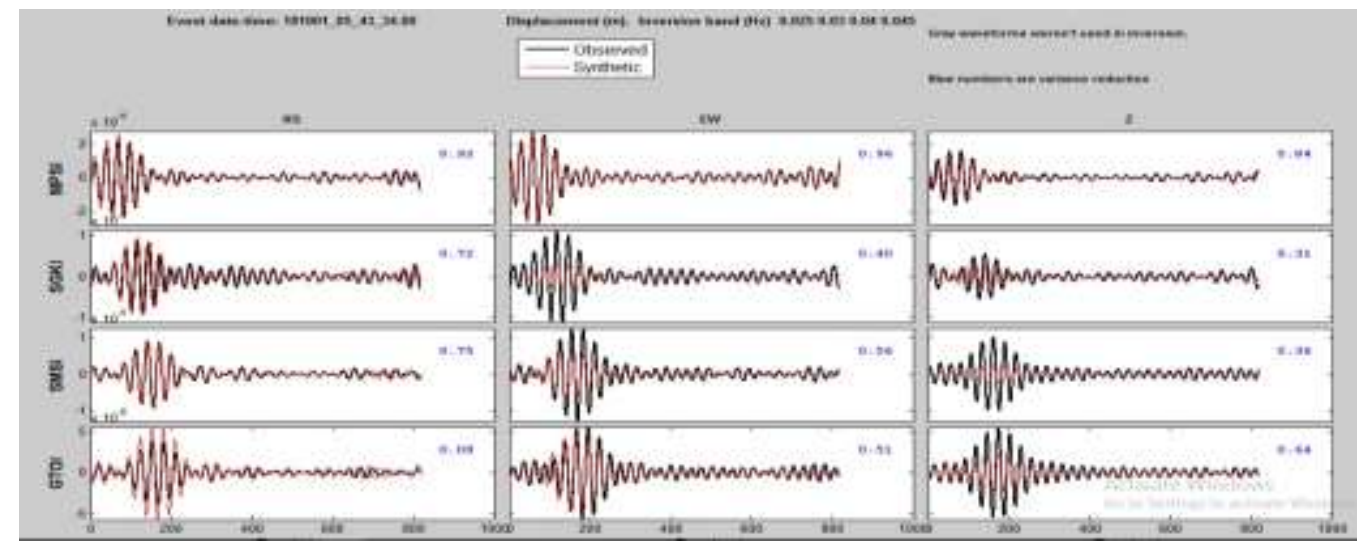

Figure 3. Observational and synthetic data showing the reduction variance value of each earthquake component and station used to process the data 
The results of the inversion of synthetic data and observations obtained the value of the reduction variance with blue numbers. The results of the different variance reduction values depend on the filtering stage and also on the Green Function stage. This variance reduction results in an accurate correlation between the black curve line (real data curve) and the red curve line (calculation curve).

\subsection{Moment tensor and focus mechanism}

After processing the data, a plot of the results is carried out. The moment tensor plot displays all the results of the Green function calculations followed by inversions such as the focus mechanism, the moment tensor size for each component, earthquake magnitude, hypocenter, earthquake recording station used for data processing, DC percent, CLVD, reduction variance and other earthquake information. Here is the moment tensor plot display with ISOLA-GUI.

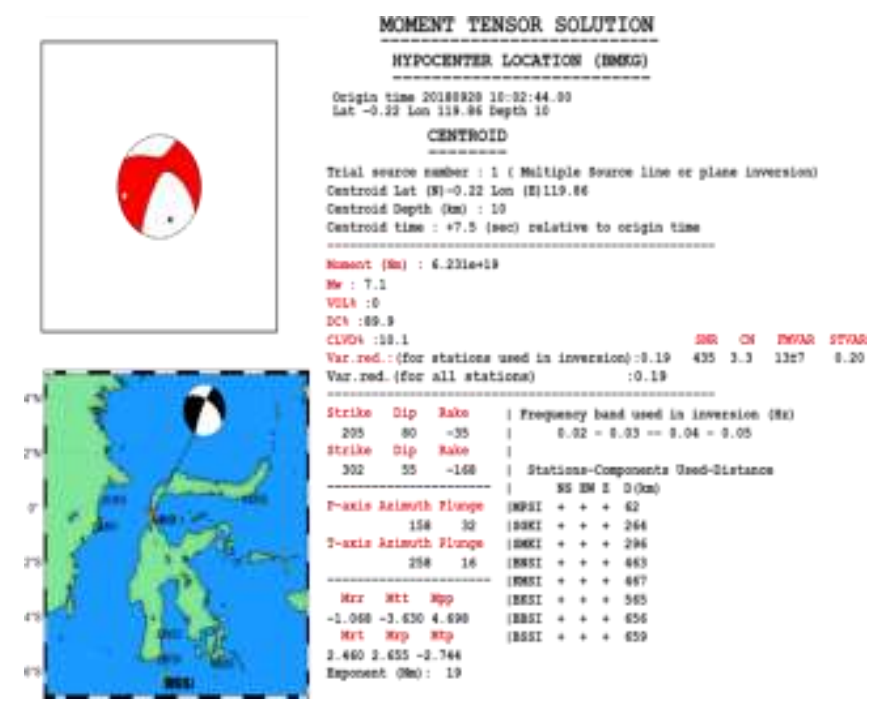

Figure 4. Mainshock event processing output

The picture above is the mainshock event processing to determine the earthquake magnitude w7.1, scalar moment of $6.231 \mathrm{e}+19 \mathrm{Nm}$ with a reduction variant of 0.19 , DC of $89.9 \%$ and CLDV of $10.1 \%$. 


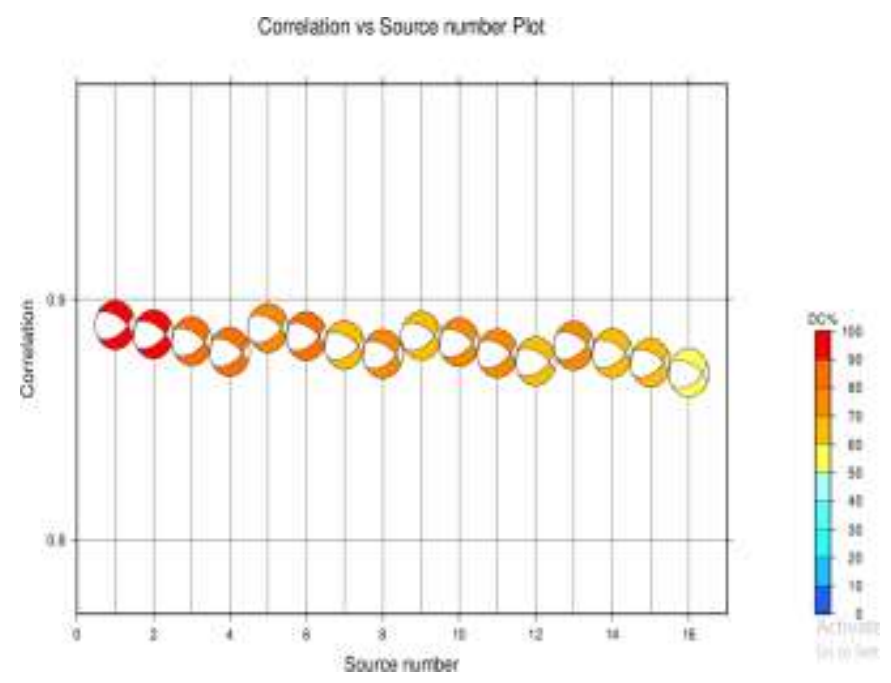

Figure 5. Plot the correlation and depth to see the exact correlation

\section{A. Earthquake foreshock analysis}

The results of the foreshock inversion obtained a reduction variant of 0.68 with a bandpass filter used 0.01-0.02 0.03-0.04 and 7 earthquake recording stations. hypocenter location $0.36^{\circ} \mathrm{S}$ and $119.8191^{\circ} \mathrm{E}$ with a depth of $10 \mathrm{~km}$, earthquake magnitude w 6, DC 84.8\%, CLDV $15.2 \%$ with the first plane characteristic of strike $=7$, dip $=88$ and rake $=-28$. While the second field is strike $=98$, dip $=62$ and rake $=-178$.

\section{B. $\quad$ Earthquake mainshock analysis}

The results of the inversion obtained a reduction variant of 0.19 with a bandpass filter used 0.02-0.03-0.04-0.05 and 8 earthquake recording stations. location of the hypocenter $0.22^{\circ} \mathrm{S}$ and $119.86^{\circ} \mathrm{E}$ with a depth of $10 \mathrm{~km}$, earthquake magnitude w 7.1, DC 89.9\%, CLDV $10.1 \%$ with the first plane characteristic of strike $=205$, dip $=80$ and rake $=-35$. While second field strike $=302$, dip $=55$ and rake $=-168$.

\section{Analysis of the first earthquake aftershock}

From the inversion, the moment tensor plot results with a reduction variance of 0.37 with a bandpass filter used 0.04-0.05-0.06-0.07 and 3 earthquake recording stations. location of the hypocenter $0.79^{\circ} \mathrm{S}$ and $120.05^{\circ} \mathrm{E}$ with a depth of $12.6 \mathrm{~km}$, earthquake magnitude w 5.5, DC $66.5 \%$, CLDV $33.5 \%$. The result of the inversion is that the characteristics of the first field are strike $=91$, dip $=73$ and rake $=-33$. While the second field is strike $=192$, dip $=58$ and rake $=-160$.

\section{Analysis of the second earthquake aftershock}

From the inversion, the moment tensor plot results obtained a reduction variant of 0.81 with the optimal bandpass filter 0.025-0.03-0.04-0.045 and 3 earthquake recording stations. location of the hypocenter $0.0004^{\circ} \mathrm{N}$ and $119.7^{\circ} \mathrm{E}$ with a depth of $12.6 \mathrm{~km}$, earthquake magnitude w 5.8, DC $98.4 \%$, CLDV $1.6 \%$. The result of the inversion shows the characteristics of the first field, 
strike $=308, \operatorname{dip}=45$ and rake $=-33$. While the second field is strike $=62$, dip $=68$ and rake $=-130$. Strike, dip, rake is a representation of the direction of slip motion.

\section{E. Analysis of the aftershock of the third earthquake}

From the inversion, the reduction variance is 0.8 with an optimal bandpass filter of 0.04-0.050.06-0.07 and 3 earthquake recording stations. location of the hypocenter $0.002^{\circ} \mathrm{N}$ and $119.67^{\circ} \mathrm{E}$ with a depth of $11.7 \mathrm{~km}$, earthquake magnitude w 5.2, DC 73.5\%, CLDV 26.5\%. The results of the inversion show the characteristics of the first large field strike $=315$, dip $=85$ and rake $=-21$. While the second field is large strike $=47$, dip $=69$ and rake $=-175$.

Table 1. Mechanism of focus for each Minahasa Peninsula earthquake event

\begin{tabular}{lclcc}
\hline Event & strike & Dip & rake & beachball \\
\hline 28/09/2018 & 7 & 88 & -28 \\
$07: 00: 01$ & 98 & 62 & -178 \\
\hline 28/09/2018 & 205 & 80 & -35 \\
$10: 02: 44$ & 302 & 55 & -168 \\
\hline $28 / 09 / 2018$ & 91 & 73 & -33 \\
$10: 50: 26$ & 192 & 58 & -160 \\
\hline $28 / 09 / 2018$ & 308 & 45 & -33 \\
$13: 35: 30$ & 62 & 68 & -130 \\
\hline $28 / 09 / 2018$ & 315 & 85 & -21 \\
$05: 43: 34$ & 47 & 69 & -175 \\
\hline
\end{tabular}

The moment tensor value for each earthquake event is as follows.

Table 2. moment tensor for each earthquake event

\begin{tabular}{|c|c|c|c|c|c|c|c|}
\hline Event & $\begin{array}{r}M_{r r=} \\
M_{33}\end{array}$ & $\begin{array}{r}M_{t t=} \\
M_{11}\end{array}$ & $\begin{array}{r}M_{p p=} \\
M_{22}\end{array}$ & $\begin{array}{r}M_{r t=} \\
M_{31}\end{array}$ & $\begin{array}{r}M_{r p=} \\
M_{32}\end{array}$ & $\begin{array}{r}M_{t p=} \\
M_{12}\end{array}$ & $\exp$ \\
\hline $\begin{array}{c}\text { 28/09/2018 } \\
07: 00: 01\end{array}$ & -0.113 & -0.302 & 0.415 & -0.049 & -0.689 & -1.229 & 18 \\
\hline $\begin{array}{c}28 / 09 / 2018 \\
10: 02: 44\end{array}$ & -1.068 & -3.630 & 4.698 & 2.460 & -2.655 & -2.744 & 19 \\
\hline $\begin{array}{c}28 / 09 / 2018 \\
10: 50: 26\end{array}$ & -0.751 & -0.778 & -0.027 & -0.761 & 0.250 & 1.579 & 17 \\
\hline $\begin{array}{c}28 / 09 / 2018 \\
13: 35: 30\end{array}$ & -3.278 & 5.523 & -2.245 & -2.229 & -2.892 & -0.701 & 17 \\
\hline $\begin{array}{c}28 / 09 / 2018 \\
05: 43: 34 \\
\end{array}$ & -1.597 & 9.403 & -7.806 & 2.192 & -2.269 & -0.373 & 16 \\
\hline
\end{tabular}

The moment tensor $(\mathrm{M})$ with units of $\mathrm{Nm}$ has different values (a negative value means that the moment tensor is in the opposite direction) but there is no significant difference. Where the value of the seismic moment is the result of activity from the fault area or midway between the two plates that are slipping. Thus, this indicates the force required to transmit seismic waves 
after an earthquake. And indirectly, this value is related to the total seismic energy caused by the fault [20].

Researchers also compared with catalogs obtained from seismological institutions that already have inversion standards. From the results of data processing with ISOLA-GUI and compared with GFZ and GCMT the results are as follows.

Table 3. Comparison of focusing mechanisms with GFZ and GCMT

\begin{tabular}{|c|c|c|c|}
\hline Event & GFZ & GCMT & Research \\
\hline $\begin{array}{c}28 / 09 / 2018 \\
07: 00: 01\end{array}$ & & & \\
\hline $\begin{array}{c}28 / 09 / 2018 \\
10: 02: 44\end{array}$ & & & \\
\hline
\end{tabular}

From the table, we can see that the mechanism of the researcher's focus has no significant difference with GFZ and GCMT, namely strike slip.

Map of the distribution of the hypocenter and the magnitude of the Minahasa Peninsula earthquake for each earthquake event as shown in Figure 6 below.

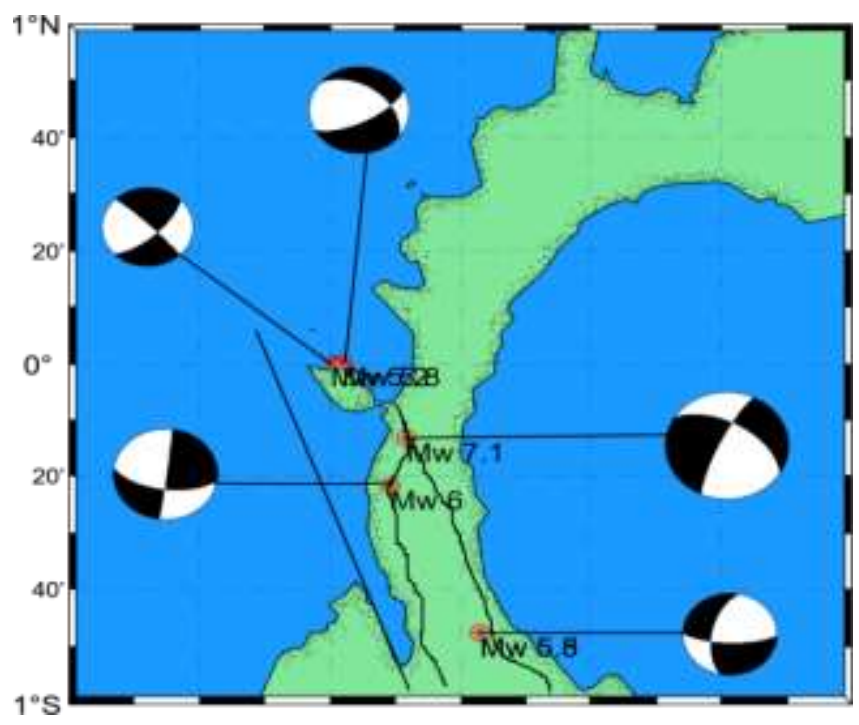

Figure 6. Map of earthquake distribution

\section{Conclusion}

From the research that has been done, it can be concluded that the fault model for all earthquake events is strike slip. The moment tensor solution for the Minahasa Peninsula earthquake or the magnitude of the moment tensor for each earthquake event, namely: 28/09/2018 07:00:01 $\left(M_{r r=} M_{33}=-0.113, M_{t t=} M_{11}=-0.302, M_{p p=} M_{22}=0.415, M_{r t=} M_{31=-0.049,} M_{r p=} M_{32}=-\right.$ 
$\left.0.689, M_{t p=} M_{12}=-1.229, \quad \exp =18\right), 28 / 09 / 201810: 02: 44\left(M_{r r=} M_{33}=-1.068, M_{t t=} M_{11}=-\right.$ 3.630, $M_{p p=} M_{22}=4.698, M_{r t=} M_{31}=2.460, M_{r p=} M_{32}=-2.655, M_{t p=} M_{12}=-2.744$, exp = 19), 28/09/2018 10:50:26 $\left(M_{r r=} M_{33}=-0.751, M_{t t=} M_{11=-0.778,} M_{p p=} M_{22}=-0.027, M_{r t=} M_{31}=-\right.$ $\left.0.761, M_{r p=} M_{32}=0.250, M_{t p=} M_{12}=1.579, \quad \exp =17\right), 28 / 09 / 201813: 35: 30\left(M_{r r=} M_{33}=-\right.$ 3.278, $M_{t t=} M_{11}=5.523, M_{p p=} M_{22}=-2.245, M_{r t=} M_{31}=-2.229, M_{r p=} M_{32}=-2.892$, $\left.M_{t p=} M_{12}=-0.701, \exp =17\right), 28 / 09 / 201805: 43: 34\left(M_{r r=} M_{33}=-1.597, M_{t t=} M_{11}=9.403\right.$, $\left.M_{p p=} M_{22}=-7.806, M_{r t=} M_{31}=2.192, M_{r p=} M_{32}=-2.269, M_{t p=} M_{12}=-0.373, \quad \exp =16\right)$. Optimal frequency filtering for variance reduction and fitting waveform curves with synthetic data for events 28/09/2018 07:00:01 =0.01-0.02-0.03-0.04, for events 28/09/2018 10:02:44= 0.02-0.03-0.04-0.05, for events 28/09/2018 10:50:26 = 0.04-0.05-0.06-0.07, for events 28/09/2018 13:35:30 = 0.025-0.03-0.04-0.045, for events 28/09/2018 05:43:34 = 0.04-0.050.06-0. The optimal frequency of each data processing for each earthquake event is different, this is influenced by the waveform recorded by the seismogram.

\section{REFERENCES}

[1] H. Grandis, Pengantar Pemodelan Inversi Geofisika, Bandung: CV. Bhumi Printing, 2009.

[2] A. Y. Baeda, "Seismic and Tsunami Hazard Potential in Sulawesi Island, Indonesia." Journal of International Development and Cooperation, vol. 17, no. 1, pp. 17-30, 2011.

[3] A. Cipta, R. Robiana, J. D. Griffin, N. Horspool, S. Hidayati and P. Cummins, "A Probabilistic Seismic Hazard Assessment for Sulawesi, Indonesia," in Geohazards in Indonesia: Earth Science for Disaster Risk Reduction, Geological Society, London, Special Publications, vol. 441, 2016.

[4] T. Kiyota, H. Furuichi, R. F. Hidayat, N. Tada and H. Nawir, "Overview of LongDistance Flow-Slide Caused by the 2018 Sulawesi Earthquake, Indonesia," Soils and Foundations, vol. 60, no. 3, pp. 722-735, 2020.

[5] K. Pakoksung, A. Suppasri, F. Imamura, C. Athanasius, A. Omang and A. Muhari, "Simulation of the Submarine Landslide Tsunami on 28 September 2018 in Palu Bay, Sulawesi Island, Indonesia, Using a Two-Layer Model," Pure and Applied Geophysics, vol. 176, pp. 3323-3350, 2019.

[6] W. Pawirodikromo, Seismologi Teknik \& Rekayasa Kegempaaan, Yogyakarta: Pustaka Pelajar, 2012.

[7] S. A. Sipkin, "Interpretation of Non-Double-Couple Earthquake Mechanisms Derived from Moment Tensor Inversion," Journal of Geophysical Research: Solid Earth, vol. 91, no. B1, pp. 531-547, 1986.

[8] D. W. Vasco, "Moment-Tensor Invariants: Searching for Non-Double-Couple Earthquakes," Bulletin of The Seismological Society of America, vol. 80, no. 2, pp. 354371, 1990.

[9] E. N. Sokos and J. Zahradník, "ISOLA A Fortran Code and A Matlab GUI to Perform Multiple-point Source Inversion of Seismic Data," Computers \& Geosciences, vol. 34, no. 8, pp. 967-977, 2008.

[10] T. Ulrich, S. Vater, E. H. Madden, J. Behrens, Y. V. Dinther, I. V. Zelst, E. J. Fielding, C. Liang and A. A. Gabriel, "Coupled, Physics-Based Modeling Reveals Earthquake 
Displacements are Critical to the 2018 Palu, Sulawesi Tsunami," Pure and Applied Geophysics, vol. 176, no. 10, pp. 4069-4109, 2019.

[11] R. N. Biswas, M. N. Islam and M. N Islam, "Modeling on Management Strategies for Spatial Assessment of Earthquake Disaster Vulnerability in Bangladesh," Modeling Earth Systems and Environment, vol. 4, pp. 1377-1401, 2018.

[12] J. Zahradník, L. Fojtíková, J. Carvalho, L. V. Barros, E. Sokos and J. Janský, "Compromising Polarity and Waveform Constrains in Focal-mechanism Solutions; the Mara Rosa 2010 Mw 4 Central Brazil Earthquake Revisited," Journal of South American Earth Sciences, vol. 63, pp. 323-333, 2015.

[13] O. Novotny, Seismic Surface Waves, Bahiar: Instituto de Fisica Instituto de Geociencias , 1999.

[14] D. Dreger and D. Helmberger, "Source Parameters of the Sierra Madre Earthquake from Regional and Local Body Waves," Geophysical Research Letters, vol. 18, no. 11, pp. 2015-2018, 1991.

[15] P. Bormann, B. Engdahl and R. Kind, "Seismic Wave Propagation and Earth Models," in New Manual of Seismological Observatory Practice 2 (NMSOP2). Deutsches Geoforschungszentrum GFZ, pp. 1-105, 2012.

[16] G-E. A. Mohamed and K. Omar, "Source Parameters and Moment Tensor of the ML 4.6 Earthquake of November 19, 2011, Southwest Sharm El-Sheikh, Egypt," NRIAG Journal of Astronomy and Geophysics, vol. 3, no. 1, pp. 27-36, 2014.

[17] J. Zahradník, and E. Sokos, "ISOLA code for multiple-point source modeling.", Moment Tensor Solutions, Springer, Cham, pp.1-28, 2018.

[18] I. Setyowidodo and B. J. Santoso, "Analisi Seismogram Tiga Komponen Terhadap Moment Tensor Gempa Bumi di Manokwari Papua 03 Januari 2009," Jurnal Neutrino, vol. 3, no. 2, pp. 113-128, 2011.

[19] S. Stein and M. Wysession, An Introduction to Seismology, Earthquakes, and Earth Structure. Oxford: Blackwell Publishing Ltd, 2003.

[20] L. E. Rachmawati and B. J. Santoso, "Estimasi Moment Tensor dan Pola Bidang Sesar pada Zona Subduksi di Wilayah Sumatera Utara Periode 2012-2014," Jurnal Sains dan Seni ITS, vol. 3, no. 2, pp. A1-A5, 2014. 